\title{
A novel, low-cost, reusable, high-fidelity neurosurgical training simulator for cerebrovascular bypass surgery
}

\author{
Ulas Cikla, MD, Balkan Sahin, MD, Sahin Hanalioglu, MD, PhD, Azam S. Ahmed, MD, \\ David Niemann, MD, and Mustafa K. Baskaya, MD \\ Department of Neurological Surgery, University of Wisconsin-Madison, Wisconsin
}

\begin{abstract}
OBJECTIVE Cerebrovascular bypass surgery is a challenging yet important neurosurgical procedure that is performed to restore circulation in the treatment of carotid occlusive diseases, giant/complex aneurysms, and skull base tumors. It requires advanced microsurgical skills and dedicated training in microsurgical techniques. Most available training tools, however, either lack the realism of the actual bypass surgery (e.g., artificial vessel, chicken wing models) or require special facilities and regulations (e.g., cadaver, live animal, placenta models). The aim of the present study was to design a readily accessible, realistic, easy-to-build, reusable, and high-fidelity simulator to train neurosurgeons or trainees on vascular anastomosis techniques even in the operating room.
\end{abstract}

METHODS The authors used an anatomical skull and brain model, artificial vessels, and a water pump to simulate both extracranial and intracranial circulations. They demonstrated the step-by-step preparation of the bypass simulator using readily available and affordable equipment and consumables.

RESULTS All necessary steps of a superficial temporal artery-middle cerebral artery bypass surgery (from skin opening to skin closure) were performed on the simulator under a surgical microscope. The simulator was used by both experienced neurosurgeons and trainees. Feedback survey results from the participants of the microsurgery course suggested that the model is superior to existing microanastomosis training kits in simulating real surgery conditions (e.g., depth, blood flow, anatomical constraints) and holds promise for widespread use in neurosurgical training.

CONCLUSIONS With no requirement for specialized laboratory facilities and regulations, this novel, low-cost, reusable, high-fidelity simulator can be readily constructed and used for neurosurgical training with various scenarios and modifications.

https://thejns.org/doi/abs/10.3171/2017.11.JNS17318

KEYWORDS bypass surgery; anastomosis; microsurgery; training; simulator

$\mathrm{T}$ HE essence of neurosurgical training is to equip fellow trainees with necessary knowledge and surgical skills through a rigorous and dedicated education process. Historically, as with other surgical specialties, the apprenticeship model has been the mainstay of neurosurgical training. ${ }^{9}$ Nonetheless, with the advent of technology in medicine, increasing public awareness of patient safety, the emergence of new concepts, and regulatory changes in education, surgical training has seen a significant paradigm shift toward proficiency-based training coupled with simulation in recent years. ${ }^{3,19,34}$ A variety of physical and virtual models, including-but not limited to-cadavers, anatomical models, mannequins, computer or web-based simulators, and virtual reality, have proved to be very powerful tools in enhancing learning experiences of trainees at various levels. ${ }^{9,17}$ These educational tools may play a role

ABBREVIATIONS CBS = cerebrovascular bypass surgery; $\mathrm{EC}=$ extracranial; $\mathrm{IC}$ = intracranial; $\mathrm{MCA}=$ middle cerebral artery; $\mathrm{NOMAT}=$ Northwestern Objective Microanastomosis Assessment Tool; STA = superficial temporal artery.

SUBMITTED February 16, 2017. ACCEPTED November 14, 2017.

INCLUDE WHEN CITING Published online May 11, 2018; DOI: 10.3171/2017.11.JNS17318. 
TABLE 1. List of materials used in the fabrication and demonstration of the bypass simulator

\begin{tabular}{|c|c|}
\hline Fabrication/Preparation & Demonstration \\
\hline Physical model of head \& brain (BrightMatter Simulate, Synaptive Medical) & Operative microscope (OPMI PENTERO 900, Zeiss) \& ICG \\
\hline Mini-submersible recirculation/water pump (Sicce, Micra) & video angiography system (INFRARED 800, Zeiss) \\
\hline Silicone/glue gun & CT scanning \\
\hline Silicone mask or any material to mimic skin & Microvascular Doppler ultrasound \\
\hline Artificial vessels (2.0 \&/or $3.0 \mathrm{~mm}$ ) (Microfixation anastomosis training kit, Biomet) & Craniotomy drill \& supplies \\
\hline Flexible plastic tubing (inner diameter $4 \mathrm{~mm}$ ) & Surgical instruments (e.g., scalpel, dissectors, forceps, \\
\hline Glass container $(1-2 \mathrm{~L})$ & microscissors, needle holders) \\
\hline Petri dish & Clip applier \& temporary aneurysm clips \\
\hline 3-way stopcock & $10-0$ nylon sutures \\
\hline \multirow[t]{2}{*}{ Other consumables (micropipette tips, silicone, gelatin, glue, water dye, water) } & ICG \\
\hline & lodinated contrast medium \\
\hline
\end{tabular}

$I C G=$ indocyanine green .

to bridge the gaps between observing, assisting, and independently practicing surgery in patients while avoiding potential harm and increasing the efficiency of the training process. Notably, novel methods that involve multiple senses, such as sight, hearing, and tactile sensation, have been shown to greatly enhance learning and education. ${ }^{11,17}$ Thus, the Congress of Neurological Surgeons has called for the incorporation of neurosurgery simulation training into residency curriculum to maximize proficiency in the most efficient way. ${ }^{9}$

Cerebrovascular bypass surgery (CBS) remains a critical neurosurgical procedure to augment or restore cerebral circulation in the treatment of some conditions, such as moyamoya disease, ${ }^{15,20}$ giant/complex aneurysms, and skull base tumors, ${ }^{8,26,28,29}$ for which there are no effective alternatives. As one of the most complex and challenging neurosurgical procedures, CBS requires dedicated training in microsurgical techniques, often in the laboratory before operating on patients. Most published methods and

TABLE 2. List of costs of the materials used in the fabrication

\begin{tabular}{lc}
\hline \multicolumn{1}{c}{ Materials } & Cost \\
\hline Artificial vessels & $\$ 42(\$ 14 \times 3)$ \\
\hline Aquarium pump & $\$ 11.99$ \\
\hline Glue gun & $\$ 3.04$ \\
\hline Flexible plastic tubing & $\$ 6.95$ \\
\hline Beaker $100 \mathrm{ml}$ & $\$ 4.49$ \\
\hline Beaker $1000 \mathrm{ml}$ & $\$ 9.99$ \\
\hline Petri dish (10 pieces) & $\$ 5.14$ \\
\hline 3-way stopcock & $\$ 6.79$ \\
\hline Red dye for water & $\$ 1.99$ \\
\hline Gelatin & $\$ 6.95$ \\
\hline Play-Doh & $\$ 0.95$ \\
\hline Glue & $\$ 2.00$ \\
\hline Cellophane & $\$ 2.78$ \\
\hline Tape & $\$ 2.44$ \\
\hline Mask (to mimic skin) & $\$ 5.99$ \\
\hline Total preparation & $\$ 113.49+x^{*}$ \\
\hline
\end{tabular}

* The $\mathrm{x}$ represents the purchase price of the skull and brain simulator. tools either do not reflect the realism of an actual CBS or are not easily accessible. Here, we describe a simplified yet efficient method to design and fabricate a low-cost, reusable, high-fidelity physical simulator incorporating all essential steps of CBS, and we also present its validation results as well as an accompanying video demonstration of superficial temporal artery-middle cerebral artery (STAMCA) bypass surgery performed using the simulator.

\section{Methods}

The materials used for the fabrication and demonstration of the simulator are listed in Table 1. Most of the materials to build the models are low-cost, easily accessible equipment and consumables (Table 2). We used a commercial composite physical model of a cranium, dura, and brain (BrightMatter Simulate, Synaptive Medical) because of its replaceable components (skull cap, brain, dura), realistic cortical surface anatomy, and imitation of tactile and haptic properties of the brain, as well as visibility with radiological imaging. The manufacturer describes 4 separate components of the kit: tray, bowl, brain with dura, and skull cap, all of which are replaceable. Although this model was used in our bypass simulator, it is not a prerequisite and any head/brain model available can be used instead.

A small aquarium-type water pump (Sicce, Micra) along with flexible tubing was used to simulate blood circulation. To better simulate extracranial (EC) donor (i.e., STA) and intracranial (IC) recipient (i.e., MCA) arteries, we used a commercially available anastomosis kit (Microfixation anastomosis training kit, Biomet), as detailed in the following section.

\section{Step-by-Step Fabrication of the Simulator Fixation of Major EC and IC Vessels}

At the first stage of preparation, we aimed to attach and stabilize all major vessels in the bowl component, avoiding any attachment to the skull cap, as the latter should be easily removable at each step and used for craniotomy on its own, thus perhaps necessitating replacement for repeated use (hence, the only component to be replaced in the long run) (Fig. 1A). Clear, flexible tubing (3-4 $\mathrm{mm}$ in diameter) was used to simulate major IC and EC vessels. 

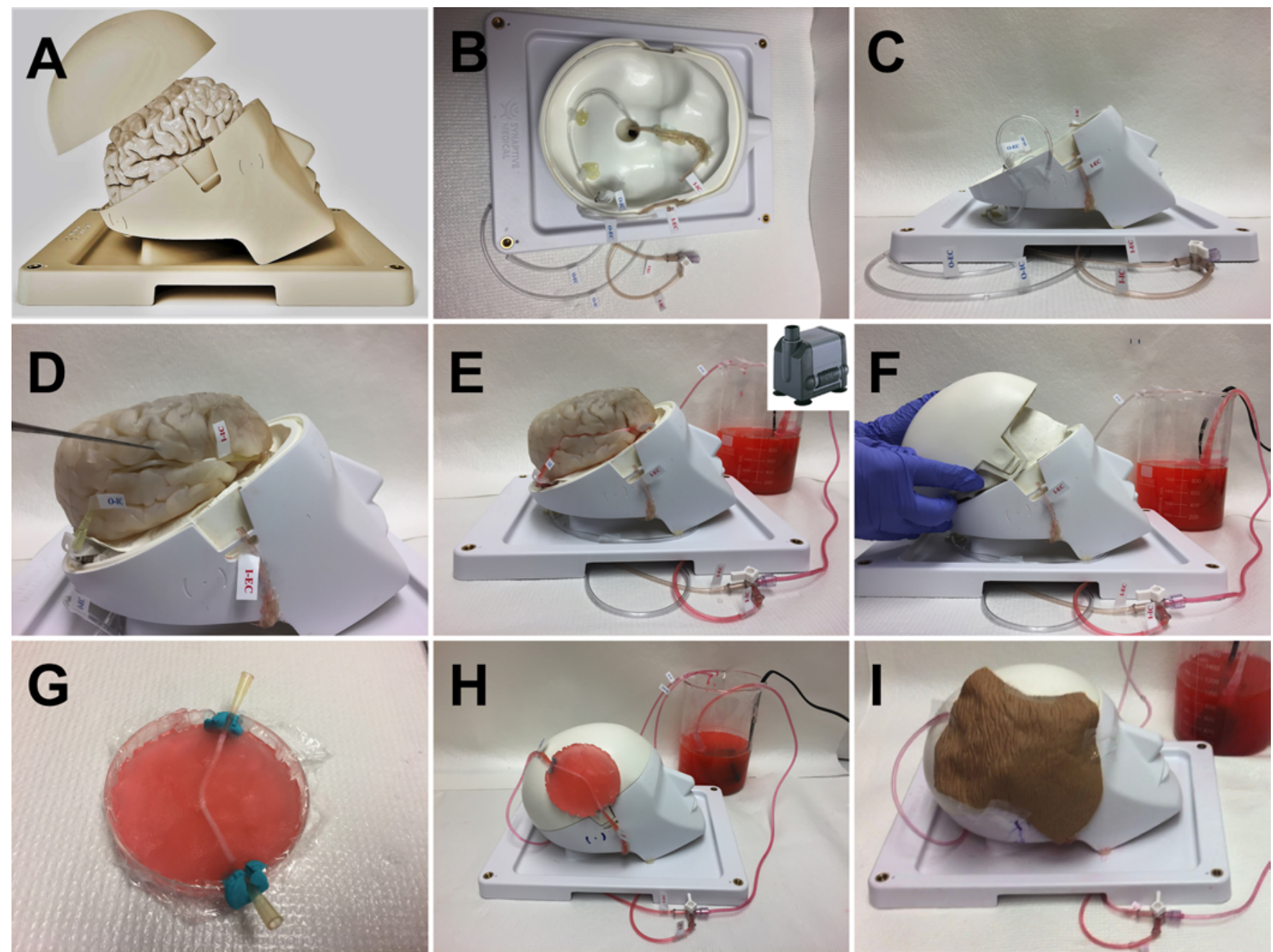

FIG. 1. Fabrication steps. A: Composite physical model of the head and brain. B and C: Attachment of major vessels. D: Placement of the MCA within the sylvian fissure. E: Recirculation pump and connection of major vessels. F: Placement of the dura (and skull cap) over the brain. G: Preparation of the STA within gelatin on a petri dish. H: Placement of STA-containing gelatin on the temporal fossa and connection with the major EC vessels. I: Placement of skin over the STA. I = input; $0=$ output.

Two separate pieces of tubing represented afferent and efferent channels (i.e., arteries and veins, also referred to as input and output) for each compartment (EC and IC). The afferent IC channel (i.e., the internal carotid artery) was affixed on the skull base with silicone so that one end exited the cranium through the central hole on the floor of the bowl and tray (representing foramen magnum), and the other end was anchored on the lateral sphenoid wing on the bowl (Fig. 1B). We affixed the efferent IC channel close to the location of sylvian fissure (parietal) and the other end again exited through the central hole. Likewise, we anchored the input EC vessel (i.e., external carotid artery) outside the cranium so that it ascended along the posterior aspect of the ramus of the mandible, ending at the level of the tragus (Fig. 1C). The efferent EC channel was the toughest to attach to the bowl because of its trajectory; however, we managed to affix it on the more posterior part of the bowl, by leaving the free end longer than usual so that it could be connected with the STA (Fig. 1H).

\section{Preparation of Vessel "Joints"}

To make the entire simulator system reusable, we designed the model with multiple replaceable elements. To do this, first, afferent and efferent tubes were attached to the artificial skull. Second, we attached both ends of the target vessels (anastomosis training kit) to the afferent and efferent tubes adequately using the micropipette tips (joints). Of note, vessels in the anastomosis kit usually come with micropipette tips attached to them; however, if other types of conduits are to be used, the attachment of micropipette tips can be customized based on the diameters of the vessel and tips.

\section{Placement of MCA in the Sylvian Fissure}

Once the MCA was connected with proximal (afferent) and distal (efferent) ends, the brain model was placed in the bowl so that the MCA sat in the sylvian fissure. At this point, both ends could be manipulated and adjusted for a better positioning of the MCA in the fissure (Fig. 1D and E). The MCA could then be covered with a thin layer of 
gelatin to mimic the arachnoid mater over and within the sylvian fissure.

\section{Installation of the Recirculation System}

We used an aquarium-type, mini-submersible recirculation pump to mimic blood circulation. First, the pump was connected with a piece of tubing (i.e., common carotid artery), which was joined with 2 afferent channels (IC and EC) via 3-way stopcock. Then, the pump was placed in a glass container filled with water stained with red dye. The distal end of the efferent IC vessel was placed over the container so that the pumped water drains back to the container (Fig. 1E). Next, we verified IC circulation with the pump turned on and 3-way stopcock, allowing flow only through the IC vessel while the EC channel was closed. After the verification of the flow through the MCA, the dura and then skull cap were replaced over the bowl (Fig. $1 \mathrm{~F})$.

\section{Preparation of the STA in a Petri Dish}

To emulate the course of the STA within subcutaneous tissue and over the temporal muscle in the temporal region, we embedded it within gelatin in a petri dish (Fig. $1 G)$. First, in the lower portion of the petri dish, a hole extending halfway down the wall was created, and the floor was covered with cellophane. A small piece of Play-Doh (Hasbro) was attached to this edge. Then, a solution was prepared by mixing $100 \mathrm{ml}$ tap water (colored, optional) and $15 \mathrm{~g}$ gelatin. Once it became slightly thickened, the mixture was poured evenly onto the petri dish to yield an approximately 6-mm thickness. After allowing the gelatin to briefly congeal (1 minute), a vessel conduit (anastomosis training kit) was carefully placed over it in a way that both ends would reunite outside the gelatin (care should be taken not to clog them with gelatin). After proper positioning of the vessel (STA), the same amount of gelatin mixture was added on top of it and left until it stabilized (30 minutes in a refrigerator at $4^{\circ} \mathrm{C}$ ).

\section{Attachment of the STA-Containing Scalp on the Cranium}

The STA-containing gelatin was removed from the petri dish with the aid of the underlying cellophane. Then the gelatin was placed over the temporal fossa appropriately and fixed on the cranium at several points with glue (Fig. $1 \mathrm{H})$. Lastly, the open ends of the STA were connected with input and output EC vessels through micropipette tips. At this step, both stable major EC vessels, particularly the output channel, could be further immobilized on the cranium using glue or tape.

\section{Verification of EC Circulation}

Once the structural connection was completed and the distal end of the output EC vessel was directed toward the container, the pump was turned on again, and the 3-way stopcock was adjusted to allow flow through the STA. Therefore, both IC and EC circulations were checked and verified.

\section{Attachment of Skin}

A commercial silicone mask or artificial skin can be used to partly or entirely cover the model to provide a more realistic interface for the simulator (Fig. 1I). With this final step, the simulator was ready for demonstration.

All steps of the preparation are shown in Video 1.

VIDEO 1. Preparation steps of the bypass simulator. Copyright Mustafa K. Baskaya. Published with permission. Click here to view.

\section{Validation Studies}

The bypass simulator was demonstrated and used by both practicing surgeons and residents at various training levels during the 3rd Microsurgery Course organized by the Departments of Neurological Surgery, Plastic Surgery, and Otolaryngology-Head and Neck Surgery at the University of Wisconsin-Madison. Twelve trained surgeons (7 faculty, 3 fellows, and 2 chief residents who had experience with microvascular anastomosis) and 12 untrained participants (senior and junior residents who did not have experience with microvascular anastomosis) provided feedback of their experience with the simulator by filling out a survey. Postcourse feedback surveys included 2 blocks. The first block included 6 questions identical to Barrow's Bypass Participant Survey. ${ }^{4}$ This block was used to evaluate face and content validity of the bypass simulator as well as those of the other training models used in the course (synthetic vessel, chicken thigh, and rat femoral artery). The first 3 questions evaluated face validity: task replication, difficulty in comparison with real surgery, and self-perception of success in accomplishing the task. The next 3 questions assessed content validity: the potential to improve microdissection and microinstrument handling skills and translation into improvements in real surgical performance. We added 4 questions, constituting the second block: 1 question ranking the available training tools in order of introduction for an ideal microvascular anastomosis training and the remaining 3 questions devoted exclusively to our simulator (perceived difficulty in fabrication, cost-effectiveness, and the recommendation of use). To analyze construct validity, we divided participants into trained and untrained groups as described above. The overall performance of each participant was assessed using the Northwestern Objective Microanastomosis Assessment Tool (NOMAT), a previously validated objective assessment scale, by trained neurosurgeons (M.K.B. and U.C.) who were familiar with the cerebrovascular techniques. ${ }^{6}$

\section{Statistical Analysis}

Data are given as mean \pm standard deviation and percentages. Statistical analyses were performed using IBM SPSS (version 22, IBM Corp.). The Mann-Whitney Utest was used for comparisons between the 2 participant groups (trained and untrained). The Kruskal-Wallis test was used for comparisons between multiple groups (training models); $\mathrm{p}<0.05$ was considered statistically significant.

\section{Results}

Demonstration of Bypass Surgery on the Simulator

A full course of an actual STA-MCA bypass surgery 
TABLE 3. Step-by-step demonstration of an actual EC-IC bypass operation on the simulator

\begin{tabular}{|c|c|c|}
\hline Step & Materials Needed & Actions \\
\hline $\begin{array}{l}\text { Step 1: position- } \\
\quad \text { ing \& prepping }\end{array}$ & $\begin{array}{l}\text { Operating table, complete bypass simulator, } \\
\text { 3-pin head holder, antiseptic skin prep }\end{array}$ & $\begin{array}{l}\text { The head is placed in a 3-pin head holder (optional) or positioned properly with } \\
\text { external fixators. The scalp is prepped with an antiseptic (optional). }\end{array}$ \\
\hline $\begin{array}{l}\text { Step 2: skin inci- } \\
\text { sion }\end{array}$ & $\begin{array}{l}\text { Microvascular Doppler ultrasound, marker } \\
\text { pen, scalpel, fish hooks/skin retractors }\end{array}$ & $\begin{array}{l}\text { Doppler ultrasound can be used to localize and mark the course of the STA on } \\
\text { the scalp. A skin incision is made along the artery. }\end{array}$ \\
\hline $\begin{array}{l}\text { Step 3: harvesting } \\
\text { donor artery }\end{array}$ & $\begin{array}{l}\text { Surgical microscope, surgical instruments, } \\
\text { scissors, forceps, dissectors }\end{array}$ & $\begin{array}{l}\text { A branch of the STA is carefully dissected from the underlying muscle. After the } \\
\text { STA is freed, the muscle is cut and folded back to expose the bone (at this step } \\
\text { gelatin can be removed for better access to bone). }\end{array}$ \\
\hline $\begin{array}{l}\text { Step 4: crani- } \\
\text { otomy }\end{array}$ & Marker pen, high-speed drill (craniotome) & $\begin{array}{l}\text { After marking the craniotomy borders, burr holes are made in the skull with a drill. } \\
\text { Then craniotomy is completed, and the bone flap is lifted and removed. }\end{array}$ \\
\hline $\begin{array}{l}\text { Step 5: opening of } \\
\quad \text { dura }\end{array}$ & $\begin{array}{l}\text { Surgical instruments, scalpel, forceps, scis- } \\
\text { sors }\end{array}$ & $\begin{array}{l}\text { Following craniotomy, dura over the brain and the sylvian fissure is opened and } \\
\text { folded back to expose the brain. }\end{array}$ \\
\hline $\begin{array}{l}\text { Step 6: preparing } \\
\text { recipient artery }\end{array}$ & $\begin{array}{l}\text { Surgical microscope, surgical instruments, } \\
\text { scissors, forceps, dissectors, rubber barrier }\end{array}$ & $\begin{array}{l}\text { Working under an operating microscope, a suitable branch of the MCA is dis- } \\
\text { sected and mobilized for bypass. Then, a rubber barrier is placed under the } \\
\text { mobilized segment of MCA for isolation. }\end{array}$ \\
\hline $\begin{array}{l}\text { Step 7: anasto- } \\
\text { mosis }\end{array}$ & $\begin{array}{l}\text { Surgical microscope, clip applier, temporary } \\
\text { clips, surgical instruments, needle holders, } \\
\text { microscissors, forceps, } 10-0 \text { nylon sutures }\end{array}$ & $\begin{array}{l}\text { Temporary clips are placed across the donor and recipient vessels to interrupt the } \\
\text { blood flow. The distal STA is prepared for anastomosis. Then the side of the } \\
\text { MCA is incised. Both open ends are sutured together under the microscope. }\end{array}$ \\
\hline $\begin{array}{l}\text { Step 8: verifying } \\
\text { flow through } \\
\text { bypass }\end{array}$ & $\begin{array}{l}\text { Surgical microscope, microvascular Doppler } \\
\text { ultrasound, ICG video angiography system, } \\
\text { ICG }\end{array}$ & $\begin{array}{l}\text { After the vessels are anastomosed, the temporary clips are released. The anas- } \\
\text { tomosis is checked for leaks. Using a Doppler ultrasound and/or ICG video } \\
\text { angiography, the patency of blood flow through the bypass is verified. }\end{array}$ \\
\hline Step 9: closure & $\begin{array}{l}\text { Surgical instruments, scissors, forceps, } \\
\text { needle holders, high-speed drill (cranio- } \\
\text { tome), sutures }\end{array}$ & $\begin{array}{l}\text { The dura is closed with sutures. Bone flap is drilled to enable the free passage of } \\
\text { bypass vessel and then replaced and fixed. Skin is sutured. After the opera- } \\
\text { tion, the simulator can be taken to the CT suite for CT angiography. lodinated } \\
\text { contrast medium should be added to the container to be pumped through the } \\
\text { vessels (optional). }\end{array}$ \\
\hline
\end{tabular}

was performed on the simulator. All 9 steps of an entire operation are described in Table 3 and Fig. 2. A demonstration is provided in Video 2.

VIDEO 2. Demonstration of the bypass surgery using the simulator. Copyright Mustafa K. Baskaya. Published with permission. Click here to view.

\section{Validation of the Simulator}

\section{Face, Content, and Construct Validity}

With scores ranging from 1 to 20 , most participants $(91.7 \%)$ scored highly (scores 15-20) the ability of the training model to replicate real bypass surgery, with no significant difference between groups (trained $17.2 \pm 2.0$ vs untrained $18.5 \pm 2.0, \mathrm{p}=0.060$ ). Most participants $(87.5 \%)$ found the difficulty of the surgery using the simulator to be similar to that of real surgery (scores 5-15), albeit slightly less difficult (trained $12.9 \pm 3.5$ vs untrained $11.3 \pm 3.0, \mathrm{p}=0.291)$. Responses only from the trained participants also show a high face validity value for the simulator. There was a significant difference in the answers between groups for the question of how successful the participant perceived himself or herself in accomplishing the task (trained $16.3 \pm 3.3$ vs untrained $12.3 \pm 4.1$, $\mathrm{p}=0.020)$. With regard to questions about the ability of the model to improve microsurgical techniques (trained $19.1 \pm 1.2$ vs untrained $17.9 \pm 2.4, \mathrm{p}=0.266)$, instrument handling (trained $18.8 \pm 1.5$ vs untrained $18.6 \pm 2.1, \mathrm{p}=$ 0.825 ), and real-life surgical performance (trained $19.3 \pm$
1.0 vs untrained $18.3 \pm 2.3, \mathrm{p}=0.410), 95.8 \%$ of participants answered positively (within the interval of 15-20) with no significant differences between the groups for the 3 questions related to content validity. Regarding the ease and cost-effectiveness of making the bypass simulator, $62.5 \%$ and $76.0 \%$ of participants, respectively, returned a positive rating (within the interval of 15-20) (ease: trained $16.3 \pm 3.4$ vs untrained $13.1 \pm 4.8, \mathrm{p}=0.078$; cost-effectiveness: trained $17.7 \pm 2.5$ vs untrained $15.6 \pm 3.1, \mathrm{p}=0.219$ ). Most participants $(87.5 \%)$ would recommend the use of the bypass simulator in their departments (scores 15-20) (trained 18.2 \pm 3.1 vs untrained 18.2 $\pm 2.3, \mathrm{p}=0.630$ ). For construct validity, performances of the 2 groups were compared using objectively assessed NOMAT scores. The trained group performed significantly higher on NOMAT than the untrained group $(63.7 \pm 3.8$ vs $41.5 \pm 7.2, p<$ 0.001).

\section{Comparison With Other Training Models}

The same questions used for the first block of postcourse evaluation survey were asked for 3 other training models (synthetic vessel, chicken thigh, and live rat). Comparative data are shown as charts for each question (Fig. 3). As expected, both live animal (i.e., rat femoral artery) and bypass simulator models were found to be more successful in replicating real surgery than synthetic vessels and the chicken thigh. Anastomosis in a live rat was deemed as the most complicated model, followed by the bypass simulator. Participants regarded themselves as sig- 

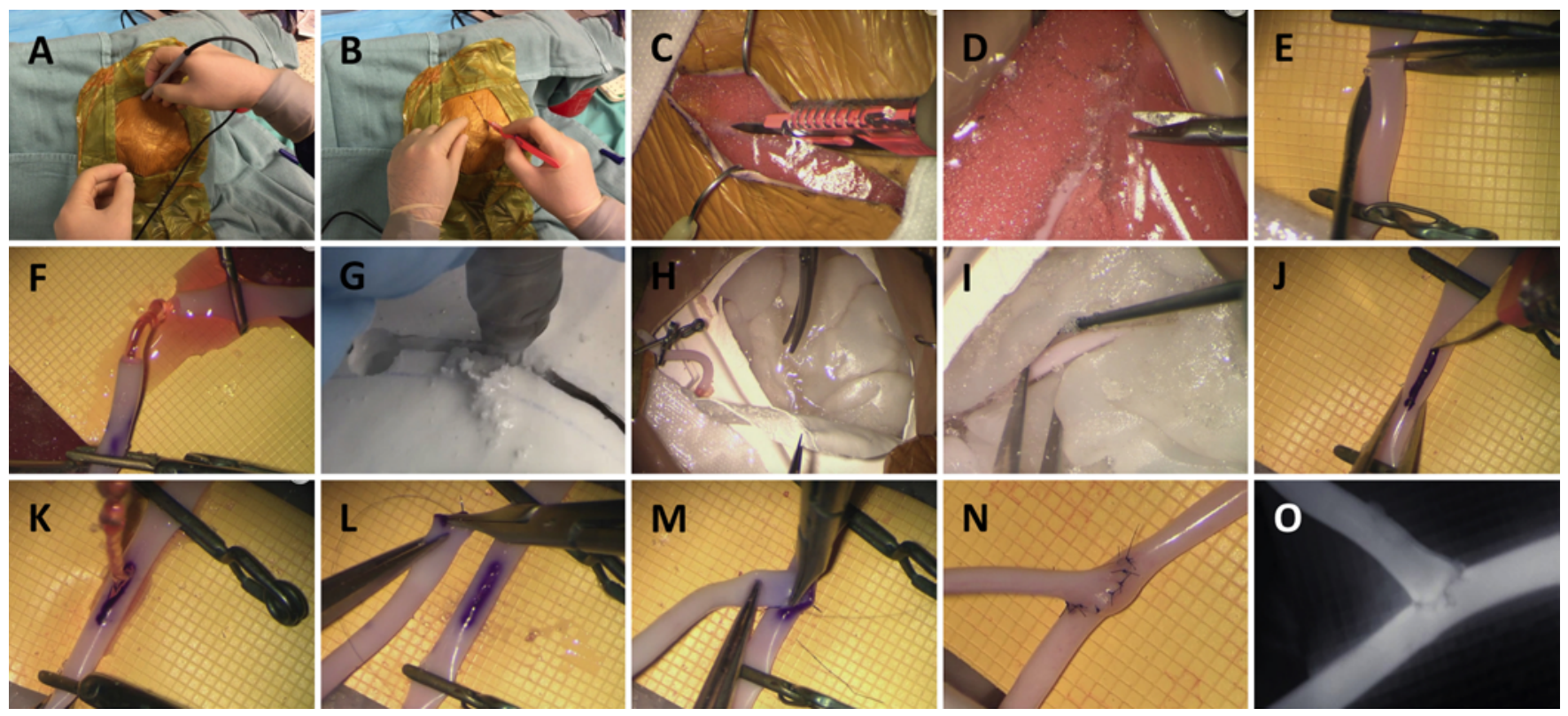

FIG. 2. Step-by-step demonstration of the STA-MCA bypass on the simulator. A: Determining the trajectory of the STA with Doppler ultrasound. B: Skin incision. C-E: Harvesting the STA. F: Verifying blood flow in the STA. G: Craniotomy with the aid of a high-speed drill. H: Dural opening. I: Dissection of the sylvian fissure and preparation of the MCA. J and K: Linear incision on MCA and verifying blood flow. L and M: End-to-side anastomosis of the STA to MCA. N: Complete anastomosis with verified patency and no leak. O: Indocyanine green video angiography confirmation of the patent bypass.

nificantly more successful with performing anastomosis in synthetic vessels than in a live animal. Although all models were considered helpful in improving microsurgical technique and instrument handling, the bypass simulator had the highest scores, although a statistically significant difference was reached only in comparison with synthetic vessels for improving microsurgical techniques (Fig. 3).

\section{Discussion}

Randomized studies from various surgical specialties have demonstrated that simulation-based education combined with deliberate practice ${ }^{19}$ or proficiency-based progression training ${ }^{3,34}$ was superior to traditional apprenticeship-type clinical education in acquiring and maintaining surgical skills. Indeed, randomized, double-blinded studies have shown that surgical resident training with a virtual reality simulator decreased both the operating time and the number of intraoperative errors significantly in comparison with the standard training group during laparoscopic surgeries. ${ }^{22,31}$ Neurosurgery will also benefit as much from simulation, and hence it should be an integral part of resident training in the future., ${ }^{9,17,30}$ To this end, various physical and virtual models have been developed to provide high-quality, time-effective training to both experienced neurosurgeons and novice trainees in a wide spectrum of neurosurgical procedures, from ventriculostomy placement to bypass surgery. ${ }^{11,17,35}$ Simulation models may, therefore, be excellent training tools to help neurosurgical trainees master their surgical knowledge and skills, and thus to prepare both physically and mentally for a real operation in a controlled environment without compromising patient safety.

CBS and anastomosis techniques remain valuable tools in the armamentarium of practicing vascular and skull base neurosurgeons. All microsurgeons excel in microsurgical work practicing on artificial vascular models, live animals, or human cadavers before operating on patients. Small animals such as rats have been used to study microanastomosis since the development of microsurgery. ${ }^{11}$ Advantages of using rats for microsurgery training include arteries that resemble small human cerebral arteries, realistic tactile and haptic features, and physiological conditions such as pulsation and coagulability.11,14,25 Despite their advantages and relatively wider availability, ethical concerns regarding animal rights, the requirement for specialized animal care facilities and financial costs are the principal drawbacks that restrict their widespread use for surgical training purposes. ${ }^{11}$ Synthetic vessel and chicken wing models have been proposed as cheaper and accessible training models. However, their main disadvantages are lack of surgical depth and spatial limits and tactile properties of tissues, blood flow, and coagulation. .11,12,16,21 $^{2}$

In the present study, we developed a novel, high-fidelity, low-cost bypass simulator that successfully resembled all necessary steps of $\mathrm{CBS}^{23}$ and is compatible with various other surgical scenarios. Validation studies confirmed the simulator's face, content, and construct validity. ${ }^{18}$ We also asked the participants to comparatively evaluate 4 different training models for microvascular anastomosis. Overall, the rat model and our bypass simulator scored better in all categories than synthetic vessels and the chicken thigh. The former two had significantly better scores for replication of real surgery. Performing the anastomosis in these models was regarded as being more difficult than that in artificial vessels. The utility of all models in improving microsurgical skills and instrument handling was similar. However, the bypass simulator was significantly better 


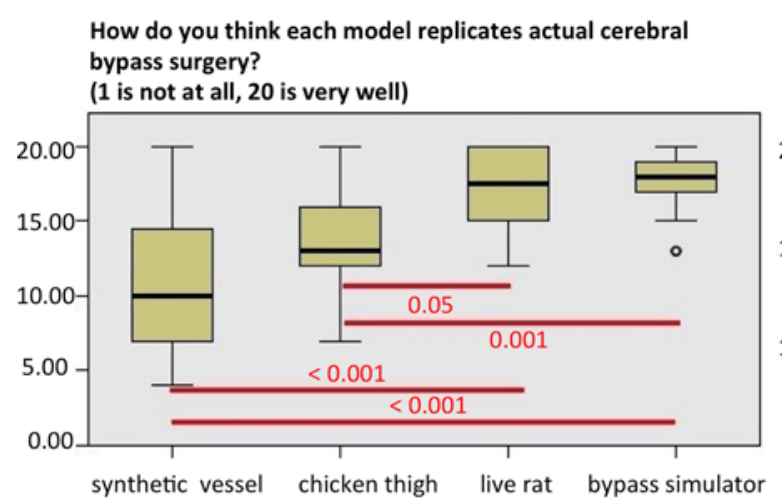

How difficult is each model compared to real surgery?

( 1 is much more difficult, 20 is much easier)

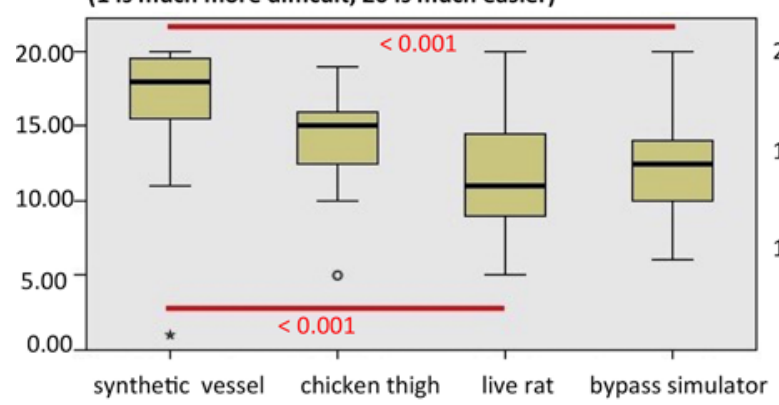

How successful were you accomplishing the tasks? ( 1 is complete failure, 20 is complete success)

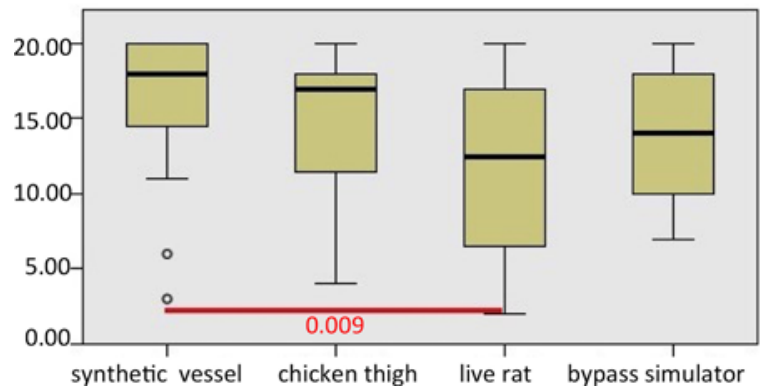

Do you think practice on each model could help to improve skills in handling microsurgical equipment? ( 1 is absolutely not, 20 is absolutely yes)

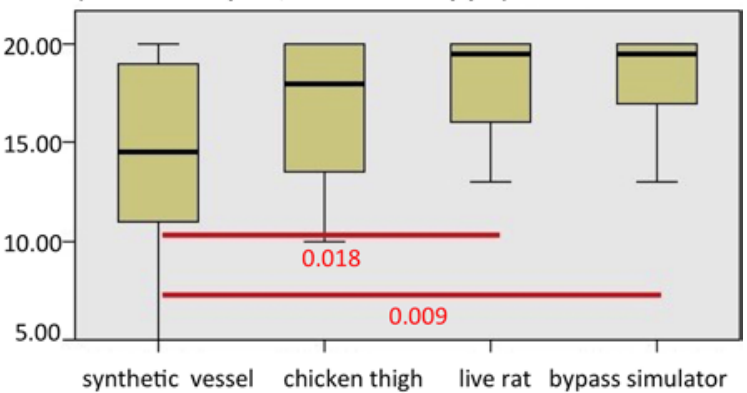

Do you think practice on each model could help to improve skills in handling microsurgical equipment?

( 1 is absolutely not, 20 is absolutely yes)

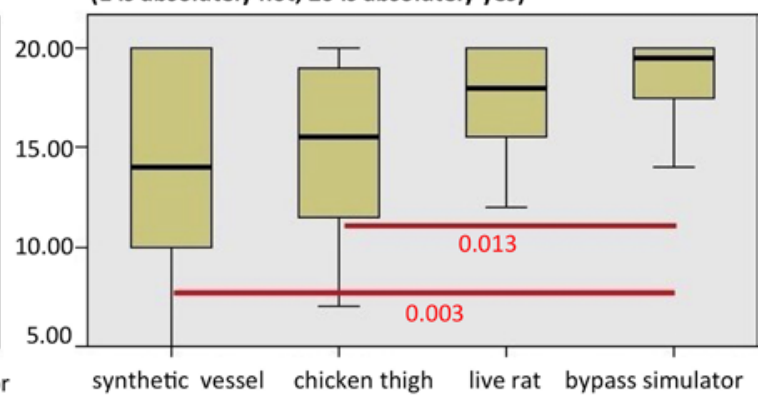

Do you think practice on each model could help to improve microsurgical technique when skills are applied to patients? ( 1 is absolutely not, 20 is absolutely yes)

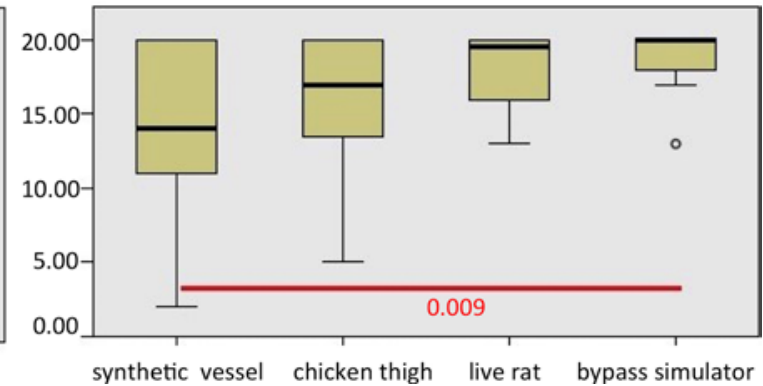

FIG. 3. Comparative analyses of 4 different training models for microvascular anastomosis evaluated by all participants $(n=24)$. The lines within the boxes indicate the median. The boxes represent the interquartile range. The whiskers indicate the entire range. Circles denote outliers.

than synthetic vessels. These results confirm the advantages of our simulator over other available training tools.

Cadaveric heads may have clear advantages over all aforementioned tools. A model mimicking all necessary aspects of neurosurgical procedures in almost real-life conditions was first developed by Aboud et al. with the pulsatile perfusion of fresh cadavers. ${ }^{2}$ Despite its clear advantages, this model as well as other cadaveric models ${ }^{10,24,27}$ carries potential infection risks, requires special facilities, and therefore is not readily available and cost-effective ${ }^{7}$ for resident training in most neurosurgical departments throughout the world.

Various animal carcasses and organs have been used for microvascular anastomosis training. ${ }^{11}$ Vessels harvested from a chicken wing, turkey neck, bovine, and human placenta can better mimic tissue properties of human vessels than artificial synthetic vessel models. ${ }^{1,4.5}$ Poultry is easily accessible, and the vessels can be infused to simulate blood flow, which makes them a low-cost alternative for surgical training. However, they are far from mimicking real anatomy, spatial restrictions, and depth of surgical field. To overcome this problem, some authors have tried to take advantage of different tools and combine them in order to circumvent the drawbacks that each model has inherently. ${ }^{13,33,36}$ For instance, Belykh et al. used human placentas placed within a 3D skull model to better simulate real surgery conditions, ${ }^{4}$ although that model poses infection risks and requires dedicated facilities. ${ }^{4}$ We believe this model can be built easily by institutions with limited resources and also individual neurosurgeons who want to practice bypass. Also, it does not possess infection risks or potential health hazards. Therefore, neurosurgeons and residents can practice on this simulator under the surgical microscope in the operating room as well. Since the 
materials used are mostly inexpensive and its fabrication is straightforward, the simulator will allow any neurosurgeon to use the operating room as a training laboratory. Once constructed, the simulator can repeatedly be used, with the replacement of only a few elements. Various scenarios (e.g., different bypasses, tumor models) can also be incorporated with minimal modifications. Furthermore, our simulator allows practicing all necessary steps (skinto-skin) of an actual CBS. Although we demonstrated the most widely used type of CBS, namely STA-MCA bypass, the simulator can also be used for bypasses with interposition grafts and in situ bypass and anastomoses. We believe that these advantages over cadavers and live animals could be widely used by neurosurgeons throughout the world.

Although our bypass simulator takes advantage of recapitulating real steps, spatial restrictions, and depth of a real CBS, it has several pitfalls. First of all, we used synthetic vessels in our model to standardize the evaluations, because various groups validated NOMAT for these vessels previously. Because it incorporates artificial vessels, the limitations inherent to these synthetic vessels, such as lack of adventitia and adherence to the surrounding tissues, also apply to our model. Adventitia removal can be simulated by covering synthetic vessels with glue or another similar material. Alternatively, a real vessel from chicken thigh or wing, large animals, or placenta can also be incorporated to the model, by attachment via "vessel joints." Second, this simulator may not seem to be inexpensive at first glance. While most of the pieces of equipment and materials are inexpensive and can be found locally, the commercial head and brain simulator account for the majority of the cost of development of our bypass simulator. However, it should be regarded as a one-time investment since it can repeatedly be used. Another solution to circumvent this could be the usage of much cheaper anatomical models, even 3Dprinted skulls. We used a particular head and brain simulator because we were able to perform radiological imaging and to benefit from its brain component that provides realistic haptic properties and texture.

Despite the incorporation of virtually all the main steps and aspects of an actual CBS in a realistic environment, the fidelity of our simulator could still be deemed inferior to living animals or cadaveric heads. However, it should be noted that this system does not require special facilities and is free of infection risks, affordable, and easily accessible; we believe that all these features make it a compelling alternative to existing training models. The tailored simulators can be readily incorporated into neurosurgery boot camps and individual training programs. ${ }^{32}$ Training with standardized simulators will not only facilitate microsurgical skill acquisition and maintenance but also make it possible to evaluate microneurosurgical skills in an objective and structured manner.

\section{Conclusions}

Mastery of CBS requires intense training to excel in microsurgical techniques. Available training tools are useful for skill training. However, they either lack essential aspects of real surgery or suffer from high costs and health risks. Here, we developed a novel, high-fidelity, low-cost bypass simulator that successfully recapitulated all necessary steps of CBS as well as is compatible with various other surgical scenarios. We believe simulators like ours will expand the availability of training opportunities for neurosurgeons worldwide who want to excel in complex microsurgical techniques.

\section{References}

1. Abla AA, Uschold T, Preul MC, Zabramski JM: Comparative use of turkey and chicken wing brachial artery models for microvascular anastomosis training. J Neurosurg 115:12311235,2011

2. Aboud E, Al-Mefty O, Yaşargil MG: New laboratory model for neurosurgical training that simulates live surgery. J Neurosurg 97:1367-1372, 2002

3. Angelo RL, Ryu RK, Pedowitz RA, Beach W, Burns J, Dodds J, et al: A proficiency-based progression training curriculum coupled with a model simulator results in the acquisition of a superior arthroscopic Bankart skill set. Arthroscopy 31:1854-1871, 2015

4. Belykh E, Lei T, Safavi-Abbasi S, Yagmurlu K, Almefty RO, Sun H, et al: Low-flow and high-flow neurosurgical bypass and anastomosis training models using human and bovine placental vessels: a histological analysis and validation study. J Neurosurg 125:915-928, 2016

5. Colpan ME, Slavin KV, Amin-Hanjani S, Calderon-Arnuphi M, Charbel FT: Microvascular anastomosis training model based on a Turkey neck with perfused arteries. Neurosurgery 62 (5 Suppl 2):ONS407-ONS411, 2008

6. El Ahmadieh TY, Aoun SG, El Tecle NE, Nanney AD III, Daou MR, Harrop J, et al: A didactic and hands-on module enhances resident microsurgical knowledge and technical skill. Neurosurgery 73 (Suppl 1):51-56, 2013

7. Grober ED, Hamstra SJ, Wanzel KR, Reznick RK, Matsumoto ED, Sidhu RS, et al: The educational impact of bench model fidelity on the acquisition of technical skill: the use of clinically relevant outcome measures. Ann Surg 240:374381,2004

8. Hanel RA, Spetzler RF: Surgical treatment of complex intracranial aneurysms. Neurosurgery 62 (6 Suppl 3):1289-1299, 2008

9. Harrop J, Lobel DA, Bendok B, Sharan A, Rezai AR: Developing a neurosurgical simulation-based educational curriculum: an overview. Neurosurgery 73 (Suppl 1):25-29, 2013

10. Hicdonmez T, Hamamcioglu MK, Tiryaki M, Cukur Z, Cobanoglu S: Microneurosurgical training model in fresh cadaveric cow brain: a laboratory study simulating the approach to the circle of Willis. Surg Neurol 66:100-104, 2006

11. Higurashi M, Qian Y,Zecca M, Park YK, Umezu M, Morgan MK: Surgical training technology for cerebrovascular anastomosis. J Clin Neurosci 21:554-558, 2014

12. Hwang G, Oh CW, Park SQ, Sheen SH, Bang JS, Kang HS: Comparison of different microanastomosis training models: model accuracy and practicality. J Korean Neurosurg Soc 47:287-290, 2010

13. Ishikawa T, Yasui N, Ono H: Novel brain model for training of deep microvascular anastomosis. Neurol Med Chir (Tokyo) 50:627-629, 2010

14. Kanazawa R, Teramoto A: The realization of preferable operative working space through the microsurgical training with rats-the importance of the process. Surg Neurol 71:380-387, 2009

15. Karasawa J, Touho H, Ohnishi H, Miyamoto S, Kikuchi H: Long-term follow-up study after extracranial-intracranial bypass surgery for anterior circulation ischemia in childhood moyamoya disease. J Neurosurg 77:84-89, 1992

16. Kim BJ, Kim ST, Jeong YG, Lee WH, Lee KS, Paeng SH: 
An efficient microvascular anastomosis training model based on chicken wings and simple instruments. J Cerebrovasc Endovasc Neurosurg 15:20-25, 2013

17. Kirkman MA, Ahmed M, Albert AF, Wilson MH, Nandi D, Sevdalis N: The use of simulation in neurosurgical education and training. A systematic review. J Neurosurg 121:228246, 2014

18. McDougall EM: Validation of surgical simulators. J Endourol 21:244-247, 2007

19. McGaghie WC, Issenberg SB, Cohen ER, Barsuk JH, Wayne DB: Does simulation-based medical education with deliberate practice yield better results than traditional clinical education? A meta-analytic comparative review of the evidence. Acad Med 86:706-711, 2011

20. Mesiwala AH, Sviri G, Fatemi N, Britz GW, Newell DW: Long-term outcome of superficial temporal artery-middle cerebral artery bypass for patients with moyamoya disease in the US. Neurosurg Focus 24(2):E15, 2008

21. Mutoh T, Ishikawa T, Ono H, Yasui N: A new polyvinyl alcohol hydrogel vascular model (KEZLEX) for microvascular anastomosis training. Surg Neurol Int 1:74, 2010

22. Nagendran M, Gurusamy KS, Aggarwal R, Loizidou M, Davidson BR: Virtual reality training for surgical trainees in laparoscopic surgery. Cochrane Database Syst Rev 27:CD006575, 2013

23. Newell DW, Vilela MD: Superficial temporal artery to middle cerebral artery bypass. Neurosurgery 54:1441-1449, 2004

24. Olabe J, Olabe J, Sancho V: Human cadaver brain infusion model for neurosurgical training. Surg Neurol 72:700-702, 2009

25. Pruthi N, Sarma P, Pandey P: Training in micro-vascular anastomosis using rat femoral vessels: comparison of immediate and delayed patency rates. Turk Neurosurg 28:56-61, 2018

26. Ramanathan D, Temkin N, Kim LJ, Ghodke B, Sekhar LN: Cerebral bypasses for complex aneurysms and tumors: longterm results and graft management strategies. Neurosurgery 70:1442-1457, 2012

27. Russin JJ, Mack WJ, Carey JN, Minneti M, Giannotta SL: Simulation of a high-flow extracranial-intracranial bypass using a radial artery graft in a novel fresh tissue model. Neurosurgery 71 (2 Suppl Operative):ons315-ons320, 2012

28. Sanai N, Zador Z, Lawton MT: Bypass surgery for complex brain aneurysms: an assessment of intracranial-intracranial bypass. Neurosurgery 65:670-683, 2009

29. Sekhar LN, Natarajan SK, Ellenbogen RG, Ghodke B: Cerebral revascularization for ischemia, aneurysms, and cranial base tumors. Neurosurgery 62 (6 Suppl 3):1373-1410, 2008

30. Selden NR, Origitano TC, Hadjipanayis C, Byrne R: Modelbased simulation for early neurosurgical learners. Neurosurgery 73 (Suppl 1):15-24, 2013
31. Seymour NE, Gallagher AG, Roman SA, O'Brien MK, Bansal VK, Andersen DK, et al: Virtual reality training improves operating room performance: results of a randomized, double-blinded study. Ann Surg 236:458-464, 2002

32. Singh P, Aggarwal R, Pucher PH, Darzi A: Development, organisation and implementation of a surgical skills 'boot camp': SIMweek. World J Surg 39:1649-1660, 2015

33. Spetzger U, von Schilling A, Brombach T, Winkler G: Training models for vascular microneurosurgery. Acta Neurochir Suppl 112:115-119, 2011

34. Stefanidis D, Scerbo MW, Montero PN, Acker CE, Smith WD: Simulator training to automaticity leads to improved skill transfer compared with traditional proficiency-based training: a randomized controlled trial. Ann Surg 255:3037, 2012

35. Tai BL, Rooney D, Stephenson F, Liao PS, Sagher O, Shih AJ, et al: Development of a 3D-printed external ventricular drain placement simulator: technical note. J Neurosurg 123:1070-1076, 2015

36. Takeuchi M, Hayashi N, Hamada H, Matsumura N, Nishijo $\mathrm{H}$, Endo S: A new training method to improve deep microsurgical skills using a mannequin head. Microsurgery 28:168-170, 2008

\section{Disclosures}

The authors report no conflict of interest concerning the materials or methods used in this study or the findings specified in this paper.

\section{Author Contributions}

Conception and design: Baskaya, Cikla, Sahin. Acquisition of data: Cikla, Sahin, Hanalioglu. Analysis and interpretation of data: Cikla, Hanalioglu. Drafting the article: Cikla, Hanalioglu. Critically revising the article: Baskaya, Cikla. Reviewed submitted version of manuscript: Baskaya, Cikla, Hanalioglu, Ahmed, Niemann. Approved the final version of the manuscript on behalf of all authors: Baskaya. Statistical analysis: Hanalioglu. Administrative/technical/material support: Baskaya, Cikla, Sahin, Ahmed. Study supervision: Cikla.

\section{Supplemental Information Videos}

Video 1. https://vimeo.com/250458685.

Video 2. https://vimeo.com/250458697.

\section{Correspondence}

Mustafa K. Baskaya: University of Wisconsin-Madison School of Medicine, Madison, WI. baskaya@neurosurgery.wisc.edu. 